\title{
Commercial Law
}

\section{Insider trading}

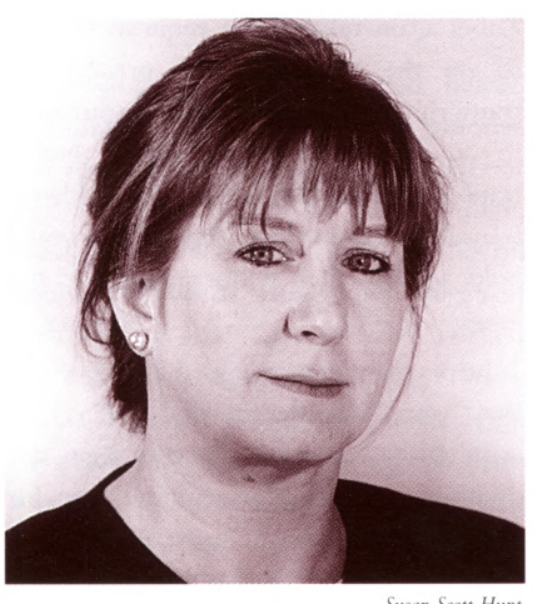

Part V of the Criminal Justice Act 1993 ('the Act'), which contains the UK's primary statutory prohibition against insider dealing, replaced, reorganised and in some respects, expanded previous criminal insider dealing legislation. The provisions of the Act overlap both the Financial Services Act 1986 (FSA) and the rules of self-regulating organisations (SROs). The Securities and Investments Board's (SIB) principles apply to the SROs and its rules have the force of law. Rule 28 prohibits knowingly effecting a transaction which contravenes the statutory restrictions. Under FSA s. 61 the SIB can take action against breaches of its own rules or those of SROs. Under the current scheme, SIB is an axis between civil, regulatory and criminal remedies.

\section{THE 1993 ACT}

Section 52 of the Act establishes three broad types of offences: dealing, disclosing and encouraging. The new general offence of 'encouraging' applies where there is knowledge or reasonable cause to believe that the object of encouragement would be likely to deal, even if he does not deal and regardless of his knowledge, either that the information comes from an insider or may be price sensitive. Thus, the offence focuses upon the mind of the insider.

The 1993 Act's definition of inside information includes material pricesensitive information relating to a specific sector, as well as to an issuer of specific securities. Section 60(4) catches any information affecting a company's 'business prospects'. It is apparent, therefore, that a decision to make a take-

\section{by Susan Scott Hunt}

over bid for securities of a particular company is capable of being inside information in regard to securities of both the target company and those in the sector within which it operates.

The 1993 Act came into effect in March 1994. Within only a few months, in August 1994, two innovative take-over transactions were begun by two corporate clients of the same integrated banking, broking and marketing operation. In both cases, the targets were recently privatised regional electricity companies (RECs). Neither transaction resulted in any criminal investigation for insider trading by the Serious Fraud Office or any other agency. Nor, in relation to either transaction, was criminal liability found to have existed. However, the transactions produced a surprising crop of issues involving interpretation of the expanded provisions of the Act and fuelled longstanding criticism of the fragmentary character of the regulatory and enforcement structures (now to be replaced by the recently christened Financial Services Authority, a unified regulatory body under SIB leadership).

\section{THE SBC CASE}

At the end of last August, in disciplinary proceedings instituted a year earlier, the Securities and Futures Authority (SFA), an SRO, 'severely reprimanded' the Swiss Bank Corporation (SBC) for breaching 'Chinese walls' in connection with one deal and a technical breach in respect of the other. Both involved the innovative use of contracts for differences (or cash performance notes). One potential application of such contracts is to provide cost coverage in a bid situation, enabling the client to benefit from an uplift in the underlying shares. The contracts at issue were custom-made off-exchange hedging mechanisms. The 1993 Act catches contracts for differences linked to shares or debt where the underlying securities are dealt with on a regulated market. It also extends to off-market dealings by or in reliance upon a professional intermediary (s. 54 and Sch. 2).

In a Board Notice (438) issued on 28 August 1997, the SFA announced it was fining SBC $£ 300,000$ plus costs. Combined with a fine in respect of unrelated misconduct, it totalled nearly half a million pounds, a record broken only by a 1995 fine against Morgan Stanley in a case involving a rogue trader. Was this a late brandishment by the SFA of its regulatory muscle - just before it is swallowed whole by the recently christened Financial Services Authority? What was the SFA's view in respect of the second bid transaction? Did either deal impact the other in a manner relevant to the likclihood of 'encouragement' occurring?

\section{PROCEDURES CRITICISED}

The SFA said SBC was being fined 'because Chinese wall procedures were not properly implemented, monitored or controlled'. The compliance department was an inappropriate intermediary. Necessary individuals should have been brought over the Chinese walls, which were, in any event, erected too late. Records of the entire procedure were inadequate.

\section{AFTER THE EVENT}

The events which culminated in the fine had all occurred more than three years earlier. In August 1994 an SBC corporate client formally notified SBC's corporate finance arm that it would consider making a bid for Yorkshire Electric ('Yorkshire'). A quote on the price of Yorkshire securities was sought for the purpose of entering into a contract for differences, with the bank acting as the counterparty. It was SBC's compliance department, charged with enforcing City rules, which acted as intermediary in approaching SBC's market makers for an indicative price. At this stage the intermediary was ignorant of the counterparty's identity and intentions. However, it is clear that Chinese walls, designed to prevent the unnecessary transfer of information within a group (thereby reducing conflicts of interest), were not implemented before the first contracts were made.

The procedures call for the intermediary to be brought over the Chinese wall in appropriate circumstances. In the next few days, six contracts pegged to Yorkshire and representing 3\% of issued share capital were entered into. SBC's 
market makers then rapidly acquired Yorkshire shares. Indeed, by the end of December, SBC held $8.2 \%, 3.7 \%$ of which was in excess of what was required to offset the bank's exposure under the contracts. Did the market makers guess or read the smoke signals about the corporate client's bid? Had SBC's corporate finance arm 'encouraged' their trading?

\section{CHINESE WALLS}

\section{The SFA said SBC was being fined:}

'... because Chinese wall procedures were not properly implemented, monitored or controlled'.

The compliance department was an inappropriate intermediary. Necessary individuals should have been brought over the Chinese walls which were, in any event, erected too late. Records of the entire procedure were inadequate. (Violations of SIB principles 3 and 9 were acknowledged. The former requires observance of high standards of market conduct, the latter, organisation and control of internal affairs.) The SFA's final finding was that the bank failed sufficiently to probe its market makers for an independently justifiable basis of confidence in the RECs (market makers acting in good faith are protected by the Act where they take a position in the market which is reasonable independently from the information. (Sch. 1).)

In fact, by the end of 1994, not only were the market makers holding a long position in Yorkshire, but SBC had increased holdings across the sector. The SFA Board Notice adds the following detail: directly after the client's notification of interest in Yorkshire, SBC's compliance department also canvassed the market makers on their willingness to become registered in respect of further RECs' securities. Further, in reality, the situation was more complicated: the Yorkshire bid was only one of two themes, the counterpoise to which involved a nearsimultaneous bid for another REC, Northern Electric. The SFA's Board Notice contains but a brief paragraph about SBC's second adventure with the RECs, noting that during this same period SBC, having inside information in relation to a second corporate client's interest in Northern Electric, also entered into (and, presumably hedged) a separate package of contracts for differences.

Nonetheless, the SFA's view seems to have been that a relatively straightforward transgression of Chinese walls took place in the (eventually aborted) bid for Yorkshire. The regulator accepted that SBC acted in good faith. The record fine may, superficially, have sent a stern signal, but will barely irritate, let alone sting. Perhaps the SFA appreciated that, whichever way it was done, SBC's market makers would have been alerted. To attempt to restrain them would only have confirmed their deductions. In this respect, the SFA solution may be viewed as a proportionate response, balancing interests in market innovation and protecting confidence in the integrity of the market.

\section{NORTHERN ELECTRIC}

In the Northern Electric bid situation, there was no intermediary. SBC's corporate finance arm passed the contracts directly to SBC's London market makers without comment. Again, under cover of their exemption from the normal requirement that all stakes in listed companies over $3 \%$ be disclosed, the market makers increased their ownership in the affected utilities - not only the bid target, but the other RECs, amongst whom numbered Yorkshire. Between the end of November and mid-December, when referral to the London Stock Exchange forced a declaration of intention to bid, Northern shares shot up.

Yet SBC circumnavigated the selfregulatory net; it was cleared of misconduct by four separate investigations into the bid for Northern. There was confusion about the overlapping jurisdictions of SROs, with regulators avoiding or delaying action because of pending probes of others. As in the bid for Yorkshire, a key issue was whether the actions of SBC's corporate finance arm 'encouraged' the market makers to buy REC shares. Before the bid, the Takeover Panel executive (whose rules mirror the previous insider dealing legislation) specifically reviewed the likelihood of the market makers' actual reaction. Arguably it was more than foreseeable, yet all the regulators conceded the scheme fell outside the regulatory structure. In respect of the bid for the second REC, the SFA found one mere technical breach of Chinese walls, the absence of an intermediary having, perhaps rightly, made the difference. In no respect, however, was the wider context, specifically the possibility of the two bids compounding the foreseeability of SBC's trading, reviewed.

At the time, institutional shareholders were incensed by SBC's non-disclosure of its REC stakes. It was argued that the City's reputation was injured by what was seen as a misuse of market makers' privileges (a claim which SBC dismissed as competitive envy of its innovative approach). Disclosure rules of large stakes built up as part of market mahing operations have since been tightened. The SIB has outlawed undisclosed derivative contracts in take-over bids. It is at least a satisfactory outcome that the situation is not likely to be repeated.

\section{PROSPECTS FOR FUTURE REGULATION}

On the road to 'Super-SIB' what wisdom is to gleaned from the wreckage (or 'REC-age') of SBC's adventures and what some saw as the disarray and timidity of City regulators? The integrated new authority will combine nine organisations, including the SROs. An outline published at its launch shows plans for a brisk-paced transitional phase, indicates its direction and promises a dedicated investigative, enforcement and disciplinary unit, handling cases across all firms and markets and providing a 'platform for a consistent approach'.

\section{TARNISHED IMAGE}

At the time, institutional shareholders were incensed by SBC's non-disclosure of its REC stakes. It was argued that the City's reputation was injured by what was seen as a misuse of market makers' privileges (a claim which SBC dismissed as competitive envy of its innovative approach). Disclosure rules of large stakes built up as part of market making operations have since been tightened.

The SIB will be required to convert itself into a comprehensive, vigorous enforcement organisation exercising authority within the blunt boundaries of commercial law, while maintaining the flexible governance function available to the current second tier SROs. The balance will not be achieved through the mere absorption of the SROs. It will require both adequate resources and a willingness to move towards a pragmatic enforcement philosophy, an appropriate element of which may be expanded civil remedies.

\section{Susan Scott Hunt}

University of Middlesex 